
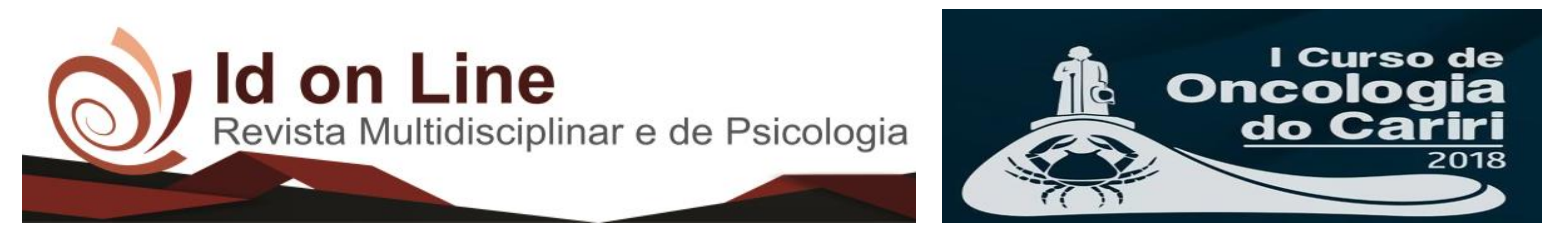

Resumo

\title{
TUMOR DE CÉLULAS GRANULARES: RELATO DE CASO
}

Ana Kelly Saraiva Filgueira Sampaio ${ }^{1}$; Ana Larisse Carneiro Pereira ${ }^{2}$; John Eversong Lucena de Vasconcelos ${ }^{3}$; Ivo Cavalcante Pita Neto

Introdução: $\mathrm{O}$ tumor de células granulares é um tumor benigno com etiologia desconhecido comumente chamado de "mioblastoma de células granulares". A lesão pode acometer pele e tecido subcutâneo, e ocasionalmente, pode ser identificado no pulmão, trato gastrointestinal, e tecido cardíaco. Na cabeça, a língua é um lugar comum para o seu surgimento. Objetivo: Apresentar as características e o tratamento do tumor de células granulares, por meio de relato de caso. Relato de caso: Paciente de 41 anos, sexo masculino, procurou o serviço de Cirurgia e Traumatologia Buco-Maxilo-Facial da Faculdade de Odontologia de Pernambuco - FOP, da Universidade de Pernambuco - UPE, com queixa principal de um "caroço" na língua. A história colhida mostrava ser assintomática, com aproximadamente 1 (um) ano de evolução, o paciente revelou não ser tabagista ou etilista. Não havia história pregressa de problemas sistêmicos associados, hospitalização ou intervenções cirúrgicas prévias. No exame clínico foi observada uma lesão nodular com $1.0 \mathrm{~cm}$ de diâmetro, localizada em dorso lingual, de base séssil, imóvel, firme e indolor à palpação. Superfície apresentando-se lisa e de coloração avermelhada. Não havia outras lesões associadas, nem linfoadenopatia cervical presente. Conclusão: Diante do caso, foi realizado a biópsia excisional sob anestesia local e análise histopatológica foi instituída, revelando diagnóstico de tumor de células granulares com hiperplasia pseudoepiteliomatosa de recobrimento de epitélio escamoso. O paciente encontra-se em acompanhamento periódico, inicialmente mensalmente e, passado um ano, semestralmente, com ausência de recidivas ou qualquer outro comprometimento, com evolução de 2 (dois) anos de pós-operatório.

Palavras-chave: Tumor de células granulares. Mioblastoma de células granulares. Cavidade Oral.

\footnotetext{
${ }^{1}$ Acadêmica de Odontologia pelo Centro Universitário - UNILEÃO, Juazeiro do Norte - CE;

${ }^{2}$ Cirurgiã Dentista pelo Centro Universitário - UNILEÃO, Juazeiro do Norte - CE;

${ }^{3}$ Doutorando em Implantodontia pela San Leopoldo Mandic, Campinas - São Paulo;

${ }^{4}$ Professor de Cirurgia e Traumatologia Buco-Maxilo-Facial no Centro Universitário - UNILEÃO, Juazeiro do Norte - CE; Autor correspondente: kelly_sara2011@ hotmail.com.
}

4 Id on Line Rev. Mult. Psic. V.12, N. 40. 2018 - ISSN 1981-1179 EDIÇÃO ESPECIAL: I CURSO DE ONCOLOGIA DO CARIRI / II JORNADA DE PESQUISA QUANTI-QUALITATIVA EM ONÇOLOGIA. JUAZEIRO DO NORTE, 05 A 10 DE MARÇO DE 2018. Edição eletrônica em http://idonline.emnuvens.com.br/id 